\title{
Advances in Mechanical Systems Dynamics
}

\author{
Alberto Doria ${ }^{1, *} \mathbb{0}$, Giovanni Boschetti ${ }^{2}$ and Matteo Massaro ${ }^{1}$ \\ 1 Department of Industrial Engineering, University of Padova, 35131 Padova, Italy; matteo.massaro@unipd.it \\ 2 Department of Management and Engineering, University of Padova, 36100 Vicenza, Italy; \\ giovanni.boschetti@unipd.it \\ * Correspondence: alberto.doria@unipd.it; Tel.: +39-049-827-6803
}

Received: 12 December 2019; Accepted: 15 December 2019; Published: 20 December 2019

check for updates

\section{Introduction}

Modern dynamics was established many centuries ago by Galileo and Newton before the beginning of the industrial era. Presently, we are in the presence of the fourth industrial revolution, and mechanical systems are increasingly integrated with electronic, electrical, and fluidic systems. This trend is present not only in the industrial environment, which will soon be characterized by the cyber-physical systems of industry 4.0 [1,2], but also in other environments like mobility, health and bio-engineering, food and natural resources, safety, and sustainable living. In this context, purely mechanical systems with a quasi-static behavior will become less common and the state-of-the-art will soon be represented by integrated mechanical systems, which need accurate dynamic models to predict their behavior. Therefore, mechanical systems dynamics is going to play an increasingly central role. Significant research efforts are needed to improve the identification of the mechanical properties of systems in order to develop models which take non-linearity into account, and to develop efficient simulation tools. This Special Issue aims at disseminating the latest research achievements, findings, and ideas in mechanical systems dynamics, with particular emphasis on the applications which are strongly integrated with other systems and require a multi-physical approach.

\section{Advances in Mechanical Systems Dynamics}

The papers collected in this Special Issue can be grouped into some topical areas of dynamics, as follows: Trajectory and motion planning, dynamic stability, vibration control and damping, control, modelling, and simulation. Most of them deal with multi-physical systems applications, including robotics, turbomachinery, vehicles, agricultural, and industrial machinery.

\subsection{Trajectory and Motion Planning}

Trajectory and motion planning are increasingly relevant in robotics and in other mechanical systems [3,4]. Indeed, the goal of achieving ever higher speeds is extending into all fields of mechanics. In order to preserve accuracy and repeatability, proper strategies should be adopted in order to generate trajectories that could be executed at high speed, while avoiding excessive motor accelerations and mechanical structure vibrations.

In Reference [5], a single leg platform for quadruped robots is designed in order to achieve high-speed locomotion. For this purpose, the foot-end trajectory for quadruped robots with a high-speed trot gait is proposed. The gait trajectory is planned for swing and stance phases. These phases are separately designed with position control and impedance control, while guaranteeing continuous and smooth transitions. Such an approach allows avoiding great rigid impact and achieving stable walking or running.

In Reference [6], a classification and a discussion of several approaches that adopt the concept of natural motion to enhance the energetic performance in robotic and mechatronic systems is presented. 
In the first part of the paper, the physical requirements that a system has to fulfill in order to exploit the natural motion are identified. While in the second part, the approaches related to natural motion are classified by trajectory types, as follows: Given trajectory, optimized trajectory, free-vibration response, and periodic trajectory learning. In the end, the methods which are able to reduce energy consumption while preserving task flexibility are highlighted.

\subsection{Dynamic Stability}

Dynamic stability is a classic topic of dynamics that, presently, has important applications in many fields of engineering, including manned and unmanned aircraft $[7,8]$, ground vehicles $[9,10]$, and walking robots [11,12]. In recent years, there have been important research developments in the field of light vehicles for urban mobility, for example, electric scooters, Segways, electrical bicycles, three-wheeled vehicles, and motorcycles [13]. In the Special Issue there are two papers which address vehicle stability.

In the first paper [14], a three-wheeled vehicle with double front wheels and single rear wheel and an active tilting mechanism is studied. A comprehensive analysis including stability, obstacle avoidance, and energy management is carried out considering the effect of both mechanical and control parameters. Results show that the developed vehicle has good handling and stability properties and is more efficient than a standard car.

The second paper [15] deals with the low speed stability of a scooter-type motorcycle. This problem is closely related to urban mobility, since congested traffic conditions limit vehicle speed, generating stability problems that require the continuous effort of the rider to stabilize the vehicle. A theoretical model is developed and validated by means of road tests. The validated model is able to predict regions of low speed stability and will be used for developing a controller.

\subsection{Vibration Control and Damping}

In recent years the interest in vibration has increased, owing to the rapid development of vibration energy harvesting technologies [16]. However, vibrations are also a potential problem for any application that includes moving components [17]. Thus, control and damping of the dynamic response is a very relevant topic. In the Special Issue there are three papers which deal with with vibration control and damping in three very different fields, as follows: Electric motors, turbines, and agricultural machines.

In Reference [18], the problem of prediction of vibrations in switched reluctance motors (SRMs) is tackled with a multi-physics approach. The comparison between the numerical and experimental data shows that the method is accurate. Therefore, it can be applied to the structural and control design optimization of SRMs.

In Reference [19], the vibrations of turbine blades are considered, while removing one the assumptions often employed, i.e., the bladed disc's rotation. The work contributes to a better understanding of the dynamics contributions to be considered when designing under-platform dampers.

In Reference [20], the dynamic behavior of a No-Till Coulter Assembly is analyzed, with a focus on the effect of magneto-rheological (MR) dampers, aimed at giving a consistent seeding depth. The comparison between the simulated and measured vertical dynamics shows good agreement with the numerical model developed. Therefore, the model can be used for the optimization of the MR dampers.

\subsection{Control}

Presently, more and more mechanical systems are being controlled, with the aim of adjusting their dynamics, e.g., pantograph/catenary [21], suspension bridges [22], gas turbines [23], motorcycles [24], etc. In this issue two challenging scenarios are considered. The first is related to laser communication, while the second is related to the control of flow separation in axial compressors. In the first paper [25], the design of a sliding mode controller to solve the nonlinear disturbance problem of a ground-based 
laser communication turntable is discussed-indeed, the alignment of the platform is a key issue in this field. Experimental results on the pitch closed-loop behavior show a better performance of the proposed (chatter-free) controller when compared to the traditional proportional, integrative, derivative (PID) and existing sliding mode.

In the second paper [26], the flow separation in axial compressors is controlled by the unsteady (pressure) excitation, not only at the shredding vortex frequency (traditional method), but also at other frequencies, demonstrating the impact on the structure of shredding vortices.

\subsection{Modelling and Simulation}

Mechanisms, gears, and transmissions are still key elements of advanced industrial systems [27]. To improve the performance of the system, detailed models of machine elements, taking into account non-linearities or time-variant properties, are needed $[28,29]$. This Special Issue includes three papers that cover the modeling and simulation of machine elements. The first paper [30] investigates the dynamics of thin walled gears and takes into account time-variant properties due to gear meshing. The method of multiple scales [31] is adopted to solve the equations of motion in the frequency domain. This method requires shorter calculation times than direct time integration methods. The results presented in this paper are important for aeronautical applications.

The second paper [32] covers a variable compression ratio engine and presents a non-linear model which includes both mechanical and hydraulic equations, similar to the models adopted for studying vehicle suspensions and shock absorbers [33]. Results show that the proposed system can achieve a continuous variation in the compression ratio of an engine, with advantages in terms of efficiency and pollution.

The third paper [34] addresses the problem of the emergency extension of nose landing gear. An interesting combination of mechanism analysis methods and statistical methods for reliability analysis is presented. The most important failure factors of an existing mechanism for emergency extension are highlighted and a more reliable mechanism is designed.

\section{Final Remarks}

In summary, this Special Issue contains a series of interesting research works focused on advances in mechanical systems dynamics, covering a wide area of applications. This collection shows the actuality of this topic and sheds light on future developments.

Author Contributions: Conceptualization, A.D., G.B., M.M.; writing-original draft preparation, A.D., G.B., M.M.; writing-review and editing, A.D., G.B., M.M.; supervision, A.D. All authors have read and agreed to the published version of the manuscript.

Funding: This research received no external funding.

Conflicts of Interest: The authors declare no conflict of interest.

\section{References}

1. Kagermann, H.; Wahlster, W.; Helbig, J. Final Report of the Industrie 4.0 Working Group, Securing the Future of German Manufacturing Industry Recommendations for Implementing the Strategic Initiative INDUSTRIE 4.0; National Academy of Science and Engineering: Frankfurt, Germany, 2013.

2. Nolting, L.; Priesmann, J.; Kockel, C.; Rödler, G.; Brauweiler, T.; Hauer, I.; Robinius, M.; Praktiknjo, A. Generating Transparency in the Worldwide Use of the Terminology Industry 4.0. Appl. Sci. 2019, 9, 4659. [CrossRef]

3. Boschetti, G.; Trevisani, A. Cable robot performance evaluation by Wrench exertion capability. Robotics 2018, 7, 15. [CrossRef]

4. Carbone, G.; Gomez-Bravo, F. Motion and Operation Planning of Robotic Systems; Springer: Heidelberg, Germany, 2015.

5. Zeng, X.; Zhang, S.; Zhang, H.; Li, X.; Zhou, H.; FuLeg, Y. Trajectory Planning for Quadruped Robots with High-Speed Trot Gait. Appl. Sci. 2019, 9, 1508. [CrossRef] 
6. Scalera, L.; Palomba, I.; Wehrle, E.; Gasparetto, A.; Vidoni, R. Natural Motion for Energy Saving in Robotic and Mechatronic Systems. Appl. Sci. 2019, 9, 3516. [CrossRef]

7. Pounds, E.I.P.; Bersak, D.R.; Dollar, A.M. Stability of small-scale UAV helicopters and quadrotors with added payload mass under PID control. Auton. Robot 2012, 33, 129-142. [CrossRef]

8. Sheng, S.; Sun, C. Design of a Stability Augmentation System for an Unmanned Helicopter Based on Adaptive Control Techniques. Appl. Sci. 2015, 5, 575-586. [CrossRef]

9. Bulsink, V.; Doria, A.; Van De Belt, D.; Koopman, B. The effect of tire and rider properties on the stability of a bicycle. Adv. Mech. Eng. 2015, 7, 1-19. [CrossRef]

10. Cossalter, V.; Doria, A.; Formentini, M.; Peretto, M. Experimental and numerical analysis of the influence of tyre's properties on the straight running stability of a sport touring motorcycle. Veh. Syst. Dyn. 2012, 50, 357-375. [CrossRef]

11. Aoi, S.; Tsuchiya, K. Generation of bipedal walking through interactions among the robot dynamics, the oscillator dynamics, and the environment: Stability characteristics of a five-link planar biped robot. Auton. Robot. 2011, 30, 123-141. [CrossRef]

12. Figliolini, G.; Ceccarelli, M. Walking programming for an electropneumatic biped robot. Mechatronics 1999, 9, 941-964. [CrossRef]

13. Limebeer, D.J.N.; Massaro, M. Dynamics and Optimal Control of Road Vehicles; Oxford University Press: Oxford, UK, 2018.

14. Haraguchi, T.; Kageyama, I.; Kaneko, T. Study of Personal Mobility Vehicle (PMV) with Active Inward Tilting Mechanism on Obstacle Avoidance and Energy Efficiency. Appl. Sci. 2019, 9, 4737. [CrossRef]

15. Singhania, S.; Kageyama, I.; Karanam, V.M. Study on Low-Speed Stability of a Motorcycle. Appl. Sci. 2019, 9, 2278. [CrossRef]

16. Tian, W.; Ling, Z.; Yu, W.; Shi, J. A Review of MEMS Scale Piezoelectric Energy Harvester. Appl. Sci. 2018, 8, 645. [CrossRef]

17. Boschetti, G.; Caracciolo, R.; Richiedei, D.; Trevisani, A. A Non-Time Based Controller for Load Swing Damping and Path-Tracking in Robotic Cranes. J. Intell. Robot. Syst. Theory Appl. 2014, 76, 201-217. [CrossRef]

18. Ling, X.; Tao, J.; Li, B.; Qin, C.; Liu, C. A Multi-Physics Modeling-Based Vibration Prediction Method for Switched Reluctance Motors. Appl. Sci. 2019, 9, 4544. [CrossRef]

19. He, S.; Jia, W.; Yang, Z.; He, B.; Zhao, J. Dynamics of a Turbine Blade with an Under-Platform Damper Considering the Bladed Disc's Rotation. Appl. Sci. 2019, 9, 4181. [CrossRef]

20. Sharipov, G.M.; Paraforos, D.S.; Griepentrog, H.W. Validating the Model of a No-Till Coulter Assembly Equipped with a Magnetorheological Damping System. Appl. Sci. 2019, 9, 3969. [CrossRef]

21. Poetsch, G.; Evans, J.; Meisinger, R.; Kortüm, W.; Baldauf, W.; Veitl, A.; Wallaschek, J. Pantograph/catenary dynamics and control. Veh. Syst. Dyn. 1997, 28, 159-195. [CrossRef]

22. Bakis, K.N.; Massaro, M.; Williams, M.S.; Limebeer, D.J.N. Aeroelastic control of long-span suspension bridges with controllable winglets. Struct. Control Health Monit. 2016, 23, 1417-1441. [CrossRef]

23. Richards, G.A.; Straub, D.L.; Robey, E.H. Passive Control of Combustion Dynamics in Stationary Gas Turbines. J. Propul. Power 2003, 19. [CrossRef]

24. Savino, G.; Lot, R.; Massaro, M.; Rizzi, M.; Symeonidis, I.; Will, S.; Brown, J. Active safety systems for powered two-wheelers: A systematic review. Traffic Inj. Prev. 2020, in press.

25. Zhang, J.; Liu, Y.; Gao, S.; Han, C. Control Technology of Ground-Based Laser Communication Servo Turntable via a Novel Digital Sliding Mode Controller. Appl. Sci. 2019, 9, 4051. [CrossRef]

26. Zhang, M.; Hou, A. Numerical Investigation on Unsteady Separation Flow Control in an Axial Compressor Using Detached-Eddy Simulation. Appl. Sci. 2019, 9, 3298. [CrossRef]

27. Barbazza, L.; Faccio Oscari, F.; Rosati, G. Agility in assembly systems: A comparison model. Assem. Autom. 2017, 37, 411-421. [CrossRef]

28. Palomba, I.; Richiedei, D.; Trevisani, A. Energy-Based Optimal Ranking of the Interior Modes for Reduced-Order Models under Periodic Excitation. Shock Vib. 2015, art. no. 348106. [CrossRef]

29. Belotti, R.; Caracciolo, R.; Palomba, I.; Richiedei, D.; Trevisani, A. An Updating Method for Finite Element Models of Flexible-Link Mechanisms Based on an Equivalent Rigid-Link System. Shock Vib. 2018, art. no. 1797506. [CrossRef] 
30. Pipitone, E.; Firrone, C.M.; Zucca, S. Application of Multiple-Scales Method for the Dynamic Modelling of a Gear Coupling. Appl. Sci. 2019, 9, 1225. [CrossRef]

31. Huang, J.; Zhang, A.; Sun, H.; Shi, S.; Li, H.; Wen, B. Bifurcation and Stability Analyses on Stick-Slip Vibrations of Deep Hole Drilling with State-Dependent Delay. Appl. Sci. 2018, 8, 758. [CrossRef]

32. Chen, J.; Wang, B.; Liu, D.; Yang, K. Study on the Dynamic Characteristics of a Hydraulic Continuous Variable Compression Ratio System. Appl. Sci. 2019, 9, 4484. [CrossRef]

33. Cossalter, V.; Doria, A.; Pegoraro, R.; Trombetta, L. On the non-linear behaviour of motorcycle shock absorbers. Proc Inst. Mech Eng Part D J. Automob. Eng. 2010, 224, 15-27. [CrossRef]

34. Zhu, Z.; Feng, Y.; Lu, C.; Fei, C. Efficient Driving Plan and Validation of Aircraft NLG Emergency Extension System via Mixture of Reliability Models and Test Bench. Appl. Sci. 2019, 9, 3578. [CrossRef]

(C) 2019 by the authors. Licensee MDPI, Basel, Switzerland. This article is an open access article distributed under the terms and conditions of the Creative Commons Attribution (CC BY) license (http://creativecommons.org/licenses/by/4.0/). 